\title{
Postmortem examination of three SARS-CoV-2-positive autopsies including histopathologic and immunohistochemical analysis
}

\author{
George-Călin Oprinca ${ }^{1,2}$ (1) $\cdot$ Lilioara-Alexandra Muja ${ }^{2,3}$
}

Received: 15 June 2020 / Accepted: 21 August 2020 / Published online: 27 August 2020

(C) Springer-Verlag GmbH Germany, part of Springer Nature 2020

\begin{abstract}
This paper describes three autopsy cases with postmortem diagnosis of SARS-CoV-2 infection, with detailed macroscopic examination as well as advanced microscopic studies of organ tissues collected using hematoxylin-eosin stains and immunohistochemical markers. Two of the cases were admitted briefly in the County Clinical Emergency Hospital of Sibiu, and one was found deceased at his home address. All three autopsies were completed at the County morgue, in the COVID-19 restricted area, using complete protective equipment. The lungs of the patients seemed to be the center organ of invasion and pathogenesis of the novel coronavirus with diffuse areas of condensation, subpleural retraction zones but with different aspect of the classic bacterial bronchopneumonia. Microscopic evaluation revealed viral cytopathic effect of type II pneumocytes with a couple of cells that presented cytoplasmic and nuclear inclusions and who tend to form clusters mimicking multinucleated giant cells. Hyaline membranes and destruction of the alveolar wall as well as microthrombi formation within the small blood vessels were constantly found in almost all our three cases. The spleen had sustained white pulp atrophy with absence of lymphoid follicles. There were no microscopic signs of viral infection on the myocardium or the other organs.
\end{abstract}

Keywords SARS-CoV-2 $\cdot$ Autopsy $\cdot$ Histopathology $\cdot$ Immunohistochemistry $\cdot$ Lung injury

\section{Introduction}

Infections with coronaviruses are widespread in humans and animals. Human pathogens include causative agents of rhinitis-like infections but also the virus of the "severe acute respiratory syndrome" (SARS), which first erupted in China in 2002 and the novel coronavirus SARS-CoV-2 with the outbreak starting in December 2019 in China [1]. The genome of CoVs is a single-stranded positive-sense RNA (+ ssRNA) $(\sim 30 \mathrm{~kb})$ with $5^{\prime}$-cap structure and 3'-poly-A tail. The

George-Călin Oprinca and Lilioara-Alexandra Muja contributed equally to this work.

George-Călin Oprinca

george_oprinca@yahoo.com

1 Department of Anatomical Pathology, County Clinical Emergency Hospital of Sibiu, Corneliu Coposu Boulevard 2-4,

550245 Sibiu, Romania

2 Faculty of Medicine, "Lucian Blaga" University of Sibiu, Lucian Blaga Street 2A, 550169 Sibiu, Romania

3 Department of Legal Medicine, County Clinical Emergency Hospital of Sibiu, Corneliu Coposu Boulevard 2-4, 550245 Sibiu, Romania genomic RNA is used as template to directly translate polyprotein $1 \mathrm{a} / 1 \mathrm{ab}$ (pp1a/pp1ab), which encodes nonstructural proteins (nsps) to form the replication-transcription complex (RTC) in double-membrane vesicles (DMVs) [2]. The COVID-19 global pandemic has put to the test not only governments worldwide but also healthcare professionals from many countries, in trying to find a way to stop the spread of the disease, to find a cure for those infected, and most of all, in finding a vaccine. All these developments can be accomplished only with the help of intense medical research. A great number of clinical studies have been published so far, but only few autopsy reports have been published. Only few histopathological and immunohistochemical studies have been released despite the length of time, more than 7 months, passed since the outbreak in Wuhan, Hubei Province of China. In order to fully understand the pathogenesis and physio-pathological manifestations of SARS-CoV-2 infections, we must first break through the unknown morphological aspects of every tissue and organ that has succumbed to the novel coronavirus, find specific or non-specific modifications within the cells and tissues, and clearly define the response of the organism on a microscopic level. After that, we can draw a map of how exactly the virus interacts with the human organism, a 
particularly important step in finding a definitive treatment for individuals affected by the virus. We feel it is particularly important for the future management of COVID-19 patients that more autopsy reports like this one should be published with no hesitations.

\section{Materials and method}

This paper describes three autopsy cases with unknown cause of death, with full macroscopic examination as well as histopathologic and immunohistochemical analysis of collected organ tissues, including the lung from which reverse transcription polymerase chain reaction (rt-PCR) tests were made to determine SARS-CoV-2 infection. All three cases were found positive postmortem. We ran one full autopsy on a 27 -yearold male found dead at his home and other two thoracoabdominopelvic autopsies. The first one was a 79-year-old woman admitted briefly to the Clinical Emergency Hospital of Sibiu County, under the suspicion of COVID-19 infection but with death occurring before a PCR test could be performed. The second thoraco-abdominopelvic autopsy of a 70 -year-old male was admitted at the same hospital. He presented with superior digestive hemorrhage but with no suspicion of infection at that time, since no respiratory symptoms or fever were present and there was no known history of contact with COVID-19-positive individuals. We performed a background check of admissions to hospital on all three cases, with detailed research of their medical records and with a thorough analysis of their complete laboratory and radiological findings. We prepared a total of approximately 40 microscopic hematoxylin-eosin slides; 10 immunohistochemical slides including CD3, CD5, CD20, and CD30 as well as cytokeratins (CK-AE1-AE3, CK-MNF116, and CK7) with a total of 250 microscopic pictures from different pathological sites of tissue and cellular changes for research purpose. All three autopsies were done in Sibiu County morgue, in the COVID-19 restricted area, using complete protective equipment.

\section{Case presentation}

\section{Case 1}

The first case presented is of a 79-year-old female patient with a history of hypertension, ischemic cardiomyopathy, and atrial fibrillation, who was hospitalized 2 months prior to death for choledochal preampular intraluminal obstruction, which was managed through endoscopic retrograde cholangiopancreatography (ERCP). Thirteen days after discharge, she presented to the emergency department with symptoms such as vomiting, abdominal pain, fatigue, loss of appetite, and productive cough. Her chest radiography showed bilateral perihilar congestive processes. She was diagnosed with acute pneumopathy and discharged from hospital with prescribed medication. After other 2 days, the patient was readmitted with a new range of symptoms such as fatigue, difficulty in breathing, and fever. A repeated chest X-ray pointed out that the congestive processes had an aggravated evolutionary aspect. Notable laboratory findings are relative clotting disorder, acute renal failure, increased white blood cell count with neutrophilia, and lymphocytopenia (Table 1). Despite comprehensive treatment, including antibiotics, corticosteroids, and assisted oxygenation, the patient's condition deteriorated, and she presented asystole without response to resuscitation, so death was declared. Subsequent clinical information confirmed that her husband, who was as well hospitalized, was found to be infected with SARS-CoV-2.

\section{Autopsy findings}

No specific pathological findings were observed upon external examination of the body. The cranial cavity was not opened. The thoracic cavity was clean, and the pleura was soft, smooth, and glassy. Multiple dark grey lymphadenopathies were discovered in the mediastinum as well as in the hilum of both the lungs, between 3 and $20 \mathrm{~mm}$ in diameter. The external aspect of the lungs was of purple dark coloration with signs of diffuse congestion. The surface had small subpleural retraction zones, and by palpation, the lungs had a more elastic consistency with lack of crepitations. Immediately after dissection of the lung, massive dark deoxygenated blood leaked from the small blood vessels, and a frothy pink fluid was discharged upon compression. The pulmonary parenchyma had a dark brown appearance with diffuse areas of condensation. The heart was increased in size, the right atrium and ventricle were dilated, and the left ventricle suffered moderate to severe eccentric hypertrophy. The myocardium had a relatively normal aspect only with loosely focal fibrotic striations. Coronary atherosclerosis was present but with preserved luminal permeability. Hepatomegaly with a "nutmeg" appearance of the liver was found, suggesting chronic passive congestion. (Table 2)

\section{Microscopic findings}

Lung architecture was modified with diffuse alveolar damage consistent with acute lung injury. The intra-alveolar septa were ruptured, with scattered lymphocytes; there was destruction of the alveolar wall with desquamation of the pneumocytes and formation of hyaline membranes, and fibrin deposits were present in the alveolar spaces. There was type II pneumocyte hyperplasia. The most important aspect we discovered was the focal type II pneumocytes that underwent cytopathic changes. There was marked enlargement (cytomegaly) of these cells with enlarged irregular nucleus with single-centered, prominent, nucleolus, and round to oval 
Table 1 Most important laboratory findings

\begin{tabular}{|c|c|c|c|}
\hline & $\begin{array}{l}\text { Case } 1 \\
79 \text {-year-old woman }\end{array}$ & $\begin{array}{l}\text { Case } 2 \\
\text { 27-year-old man }\end{array}$ & $\begin{array}{l}\text { Case } 3 \\
\text { 70-year-old man }\end{array}$ \\
\hline Leukocyte count & $11.8910^{3} / \mathrm{ul}$ (High) & - & $15.5310^{3} / \mathrm{ul}$ (high) \\
\hline Erythrocyte count & $4.8210^{6} / \mathrm{ul}$ & - & 1.15 10\%/ul (low) \\
\hline Hemoglobin & $13.8 \mathrm{~g} / \mathrm{dl}$ & - & $3.8 \mathrm{~g} / \mathrm{dl}$ (low) \\
\hline Neutrophil count & $10.7110^{3} /$ ul (high) & - & $10.6410^{3} / \mathrm{ul}$ (high) \\
\hline Lymphocyte count & $0.6310^{3} / \mathrm{ul}$ (low) & - & $3.8110^{3} / \mathrm{ul}$ \\
\hline Thrombocyte count & $34410^{3} / \mathrm{ul}$ & - & $24810^{3} / \mathrm{ul}$ \\
\hline $\mathrm{C}$ reactive protein & 307.17 mg/l (high) & - & $14.12 \mathrm{mg} / \mathrm{l}$ (high) \\
\hline Creatinine & 1.46 mg/dl (high) & - & $3.68 \mathrm{mg} / \mathrm{dl}$ (high) \\
\hline PT (s) & 27.7 s (high) & - & 124.7 s (high) \\
\hline Prothrombin activity & $26.2 \%$ (low) & - & $5.5 \%$ (low) \\
\hline APTT & $50.0 \mathrm{~s}$ (high) & - & $80.8 \mathrm{~s}$ (high) \\
\hline INR & 2.62 (high) & - & 13.00 (high) \\
\hline Procalcitonin & $0.09 \mathrm{ng} / \mathrm{ml}$ & - & - \\
\hline
\end{tabular}

inclusions situated at the periphery of the nucleus and surrounded by clear halo. The cytoplasm was rich, eosinophilic, and lacked viral inclusions. In some areas, these cells tend to form clusters and imitate multinucleated giant cells and are defined as multinucleated giant cell-like pneumocyte aggregates. Upon further examination of the lung parenchyma, we

Table 2 Summary of autopsy findings and data

\begin{tabular}{|c|c|c|c|}
\hline Organ/system & $\begin{array}{l}\text { Case } 1 \\
79 \text {-year-old woman } \\
165 \mathrm{~cm} 65 \mathrm{~kg}\end{array}$ & $\begin{array}{l}\text { Case } 2 \\
27 \text {-year-old man } \\
181 \mathrm{~cm} 114 \mathrm{~kg}\end{array}$ & $\begin{array}{l}\text { Case } 3 \\
70 \text {-year-old man } \\
175 \mathrm{~cm} 73 \mathrm{~kg}\end{array}$ \\
\hline $\begin{array}{l}\text { Lungs/respiratory } \\
\text { system }\end{array}$ & $\begin{array}{l}\text { Right lung }-925 \mathrm{~g} \\
\text { Left lung- }-890 \mathrm{~g} \\
\text { Massive pulmonary congestion with diffuse } \\
\text { patchy areas of condensation. Mild } \\
\text { pulmonary edema }\end{array}$ & $\begin{array}{l}\text { Right lung-1315 g } \\
\text { Left lung - } 1287 \mathrm{~g} \\
\text { Massive pulmonary congestion with } \\
\text { diffuse patchy areas of } \\
\text { condensation. Moderate } \\
\text { pulmonary edema }\end{array}$ & $\begin{array}{l}\text { Right lung- }-855 \mathrm{~g} \\
\text { Left lung- } 842 \mathrm{~g} \\
\text { Bilateral pleural effusion } 250 \mathrm{ml} \text { of clear } \\
\text { serous fluid. Patchy areas of } \\
\text { condensation within the middle right } \\
\text { lobe and inferior bilateral lobes. Mild to } \\
\text { moderate pulmonary congestion. } \\
\text { Emphysema of the superior lobes }\end{array}$ \\
\hline $\begin{array}{l}\text { Heart/cardiovascular } \\
\text { system }\end{array}$ & $\begin{array}{l}355 \mathrm{~g} \\
\text { Dilated cardiomyopathy, left ventricular } \\
\text { hypertrophy, right atrial and ventricular } \\
\text { dilatation. Coronary atherosclerosis. } \\
\text { Aortic atherosclerosis }\end{array}$ & $\begin{array}{l}342 \mathrm{~g} \\
\text { Right atrial and ventricular dilatation. } \\
\text { In the rest, no morphological } \\
\text { abnormalities of the myocardium, } \\
\text { coronary arteries, or aorta }\end{array}$ & $\begin{array}{l}412 \mathrm{~g} \\
\text { Ischemic cardiomyopathy, left ventricular } \\
\text { hypertrophy, right atrial and ventricular } \\
\text { dilatation. Severe coronary } \\
\text { atherosclerosis. Aorto-coronary bypass. } \\
\text { Complicated aortic atherosclerosis }\end{array}$ \\
\hline $\begin{array}{l}\text { Kidneys/urinary } \\
\text { system }\end{array}$ & $\begin{array}{l}\text { Right kidney-10.5-cm length; } 5.2-\mathrm{cm} \\
\text { width; } 126 \mathrm{~g} \\
\text { Left kidney-10-cm length; } 5 \text {-cm width; } \\
122 \mathrm{~g} \\
\text { Small subcapsular cysts }(0.5-1 \mathrm{~cm} \text { in } \\
\text { diameter). Mild renal medullary } \\
\text { congestion }\end{array}$ & $\begin{array}{l}\text { Right kidney-12-cm length; } 7-\mathrm{cm} \\
\text { width; } 145 \mathrm{~g} \\
\text { Left kidney-11.5-cm length; } \\
6.5-\mathrm{cm} \text { width; } 139 \mathrm{~g} \\
\text { Normal macroscopic aspect of the } \\
\text { kidneys }\end{array}$ & $\begin{array}{l}\text { Right kidney-10.8-cm length; } 5.7-\mathrm{cm} \\
\text { width; } 110 \mathrm{~g} \\
\text { Left kidney-11.1 cm length; } 5.8-\mathrm{cm} \\
\text { width; } 118 \mathrm{~g} \\
\text { Mild renal medullary congestion }\end{array}$ \\
\hline $\begin{array}{l}\text { Liver/hepatobiliary } \\
\text { system }\end{array}$ & $\begin{array}{l}1825 \mathrm{~g} \\
\text { Hepatomegaly. "Nutmeg liver" of chronic } \\
\text { passive congestion }\end{array}$ & $\begin{array}{l}1750 \mathrm{~g} \\
\text { No morphological abnormality }\end{array}$ & $\begin{array}{l}2250 \mathrm{~g} \\
\text { Hepatomegaly. Macro- and micronodular } \\
\text { cirrhosis }\end{array}$ \\
\hline $\begin{array}{l}\text { Spleen/immune } \\
\text { system }\end{array}$ & $\begin{array}{l}131 \mathrm{~g} \\
\text { Spleen of normal morphology on a } \\
\text { macroscopic level. Multiple pulmonary } \\
\text { hilar and mediastinal lymphadenopathies } \\
\text { between } 3 \text { and } 20 \mathrm{~mm} \text { in diameter }\end{array}$ & $\begin{array}{l}147 \mathrm{~g} \\
\text { Spleen of normal morphology on a } \\
\text { macroscopic level }\end{array}$ & $\begin{array}{l}102 \mathrm{~g} \\
\text { Small spleen. Amyloid deposits on spleen } \\
\quad \text { surface }\end{array}$ \\
\hline
\end{tabular}


came across focal areas of rich polymorphonuclear infiltration, composed of mainly neutrophils, which translates as focal areas of bacterial superposition. Also, we must mention that there were areas of intra-alveolar proteinaceous exudate, capillary congestion, and amylaceous bodies present in examined sections (Fig. 1 and Table 3).

Upon microscopic examination of the heart, we concluded that there were no specific pathological changes indicating viral myocarditis. There was a mild to moderate perivascular edema and vascular congestion. Areas of small contraction band-like lesions were seen, and there were only a few scattered lymphocytes between the myocardial fibers.

Microscopic examination of the liver revealed a preserved lobular architecture with some degree of centrilobular vascular congestion. The hepatocytes had intracellular large clear droplets defined as macrovesicular steatosis. There was periportal fibrosis with focal porto-portal and porto-central bridging fibrosis and a mild to moderate lymphocytic infiltrate contained within the portal tract, most probably secondary to obstructive biliary disease. The biliary ducts were of a normal architecture.

The renal parenchyma studied had relatively unspecific changes. There were some glomeruli loss in the renal cortex most probably due to age, and we identified the presence of focal microthrombi formation within the glomerular capillary lumen, but no other specific morphologic abnormality was evident upon studying the glomeruli architecture. The proximal convoluted tubules had suffered loss of cytoplasmic and nuclear detail (rarefaction) and retraction of tubule epithelial cells from basement membranes, most probably due to the autopsy being performed $24 \mathrm{~h}$ later after death. We identified only small areas of acute tubular injury with coagulative necrosis of focal tubular epithelial cells. There was passive congestion within the medullary blood vessels. No inflammatory cells could be identified in the sampled specimen that was examined, and there were no viral cytopathic changes within the renal cells.

Microscopy of the spleen showed autolytic changes but also disorganization of spleen compartments translated by marked congestion with white pulp atrophy and with the absence of lymphoid follicles. The remaining lymphoid tissue was found around the central arteries. The capsule was intact (Fig. 2).

On the lung samples from this case, we managed to perform immunohistochemistry studies, to be able to understand exactly which type of cells was involved in the pathogenesis of SARS-CoV-2. Pancytokeratin panels (CKAE1-AE3; CK-MNF116) most importantly found positivity within hyaline membranes, corroborating the fact that these membranes formed by destruction of the epithelial lining, and they had no fibrin origin. Cytokeratin 7 (CK7) was reactive in pneumocytes that underwent viral cytopathic effect, including in clusters of giant celllike pneumocytes aggregates. We also found that CK7
Fig. 1 Microscopic aspect of lung (case 1) -hematoxylin-eosin ( $\times$ $100, \times 400)$. a (arrow) $(\times 400) ; \mathbf{b}$ (arrow head) $(\times 400)$ Type II pneumocyte hyperplasia with viral cytopathic effect forming clusters and imitating multinucleated giant cells. c $(\times$ 100) Hyaline membranes (black triangle) and scattered lymphocytes within the alveolar septum (red triangle). d $(\times 400)$ Focal area of neutrophilic inflammatory infiltrate
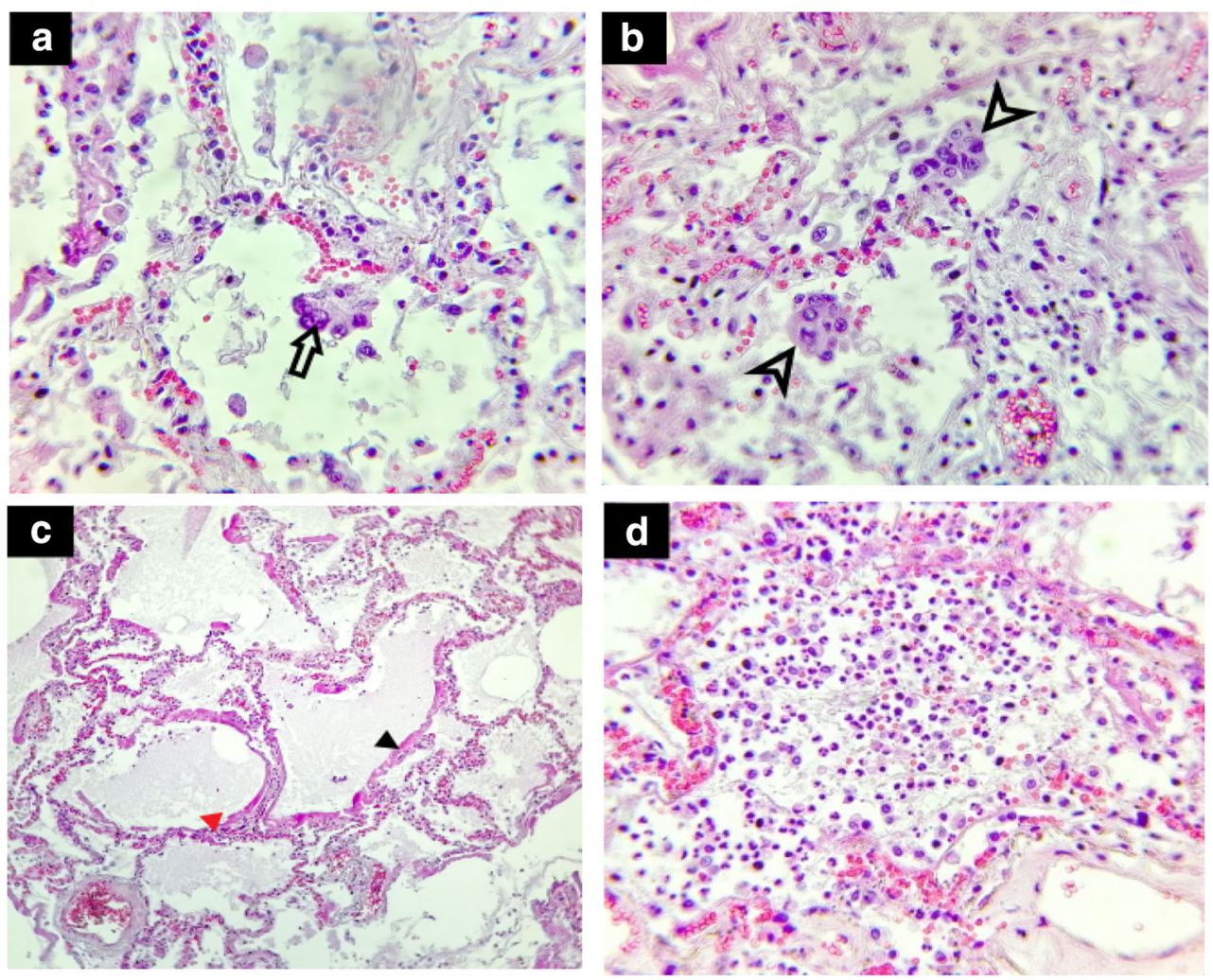
Table 3 Summary of microscopical findings

\begin{tabular}{|c|c|c|c|}
\hline Organ & $\begin{array}{l}\text { Case } 1 \\
79 \text {-year-old woman }\end{array}$ & $\begin{array}{l}\text { Case } 2 \\
27 \text {-year-old man }\end{array}$ & $\begin{array}{l}\text { Case } 3 \\
70 \text {-year-old man }\end{array}$ \\
\hline Lungs & $\begin{array}{l}\text {-Rupture of intra-alveolar septum } \\
\text {-Pneumocyte detachment } \\
\text {-Hyaline membrane formation } \\
\text {-Fibrin deposits in the alveolar spaces } \\
\text {-Type II pneumocyte hyperplasia } \\
\text {-Focal type II pneumocytes with } \\
\text { cytopathic changes } \\
\text {-Multinucleated giant cell-like } \\
\text { pneumocyte aggregates } \\
\text {-Focal areas of rich neutrophilic } \\
\text { infiltration } \\
\text {-Scattered areas of interstitial } \\
\text { lymphocytic inflammatory infiltration }\end{array}$ & $\begin{array}{l}\text {-Destruction of the alveolar wall lining } \\
\text {-Focal presence of hyaline membranes } \\
\text {-Intra-alveolar hemorrhage } \\
\text {-Large numbers of hemosiderin-laden } \\
\text { macrophages within the alveolar space } \\
\text {-Mild pneumocyte hyperplasia } \\
\text {-Focal type II pneumocytes with cytopathic } \\
\text { changes } \\
\text {-Multinucleated giant cell-like pneumocyte } \\
\text { aggregates } \\
\text {-Interstitial, perivascular and peribronchial } \\
\text { lymphocytic inflammatory infiltration } \\
\text {-Mild vasculitic reaction in some vessel } \\
\text { walls } \\
\text {-Focal areas of rich neutrophilic infiltration } \\
\text {-Microthrombi of the small vessels }\end{array}$ & $\begin{array}{l}\text {-Detachment of the alveolar lining with scattered } \\
\text { pneumocytes within the alveolar space } \\
\text {-Moderate type II pneumocyte hyperplasia } \\
\text {-Focal type II pneumocytes with cytopathic changes } \\
\text {-Mild to moderate lymphocytic inflammatory } \\
\text { reaction, more expressed in the perivascular } \\
\text { region } \\
\text {-Mild vasculitic reaction in some vessel walls } \\
\text {-Microthrombi of the small vessels }\end{array}$ \\
\hline Heart & $\begin{array}{l}\text {-Mild to moderate perivascular edema } \\
\text { vascular congestion } \\
\text {-Areas of small contraction band-like } \\
\text { lesions } \\
\text {-Small number of scattered lymphocytes } \\
\text { between the myocardial fibers }\end{array}$ & $\begin{array}{l}\text {-Small vessel thrombosis } \\
\text {-Marked vascular congestion } \\
\text {-Mild edema between the muscle fibers } \\
\text {-Myocardial fibers that tend to form } \\
\text { contraction bands }\end{array}$ & $\begin{array}{l}\text {-Myocardosclerosis } \\
\text {-Old myocardial infarction } \\
\text {-Mild edema } \\
\text {-Marked vascular congestion } \\
\text {-Acute circulatory disorders }\end{array}$ \\
\hline Kidneys & $\begin{array}{l}\text {-Focal microthrombi formation within } \\
\text { the glomerular capillary lumen } \\
\text {-Small areas of acute tubular injury with } \\
\text { coagulative necrosis }\end{array}$ & & $\begin{array}{l}\text {-Shrunken glomeruli with enlarged Bowman space } \\
\text {-Acute tubular necrosis }\end{array}$ \\
\hline Liver & $\begin{array}{l}\text {-Centrilobular vascular congestion } \\
\text {-Macro-vesicular steatosis } \\
\text {-Periportal fibrosis with focal porto-portal } \\
\text { and porto-central bridging fibrosis } \\
\text {-Mild to moderate lymphocytic infiltrate } \\
\text { contained within the portal tract }\end{array}$ & & $\begin{array}{l}\text {-Regenerative nodules porto-portal bridging fibrosis } \\
\text {-Scattered lymphocytes within the portal areas }\end{array}$ \\
\hline Spleen & $\begin{array}{l}\text {-Marked congestion white pulp atrophy } \\
\text { absence of lymphoid follicles }\end{array}$ & & $\begin{array}{l}\text {-Marked congestion white pulp atrophy absence of } \\
\text { lymphoid follicles }\end{array}$ \\
\hline
\end{tabular}

immunostain was forming cytoplasmic halos of nonreactivity in a small number of cytopathic cells revealing possible cytoplasmic viral inclusions. Focal areas of lymphocytic infiltrates described earlier were reactive to CD3

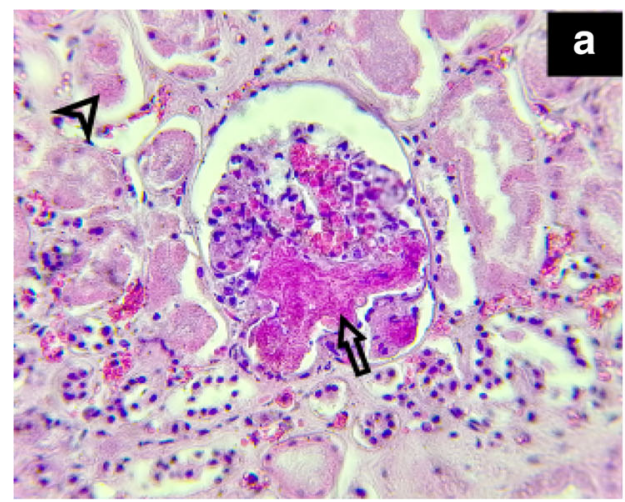

Fig. 2 Microscopic aspect kidney and spleen (case 1)- hematoxylineosin $(\times 100, \times 400)$. a Kidney $(\times 400)$ Focal microthrombi formation within the glomerular capillary lumen (arrow). Acute tubular injury and CD5, and only scattered lymphocytes were found positive to CD20 in the examined lung tissue. CD23 and CD30 were found negative in every sample examined (Fig. 3).

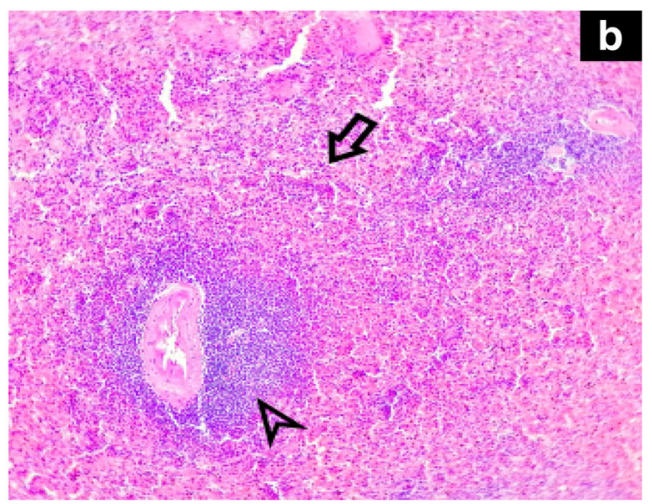

(arrow head). b Spleen $(\times 100)$ Marked congestion with white pulp atrophy (arrow), the remaining lymphoid tissue was found around the central arteries (arrow head) 
Fig. 3 Immunohistochemistry study of lung (case 1$)-(\times 100, \times$ 400). a (arrows) $(\times 100)$ Pancytokeratin-positive hyaline membranes. b $(\times 400)$ CD3positive lymphocytes. c (arrow head) $(\times 400)$ CK 7-positive giant cell-like pneumocytes aggregates with viral cytopathic effect. d (triangle) $(\times 400)$ Type II pneumocyte with viral effect and cytoplasmic inclusions
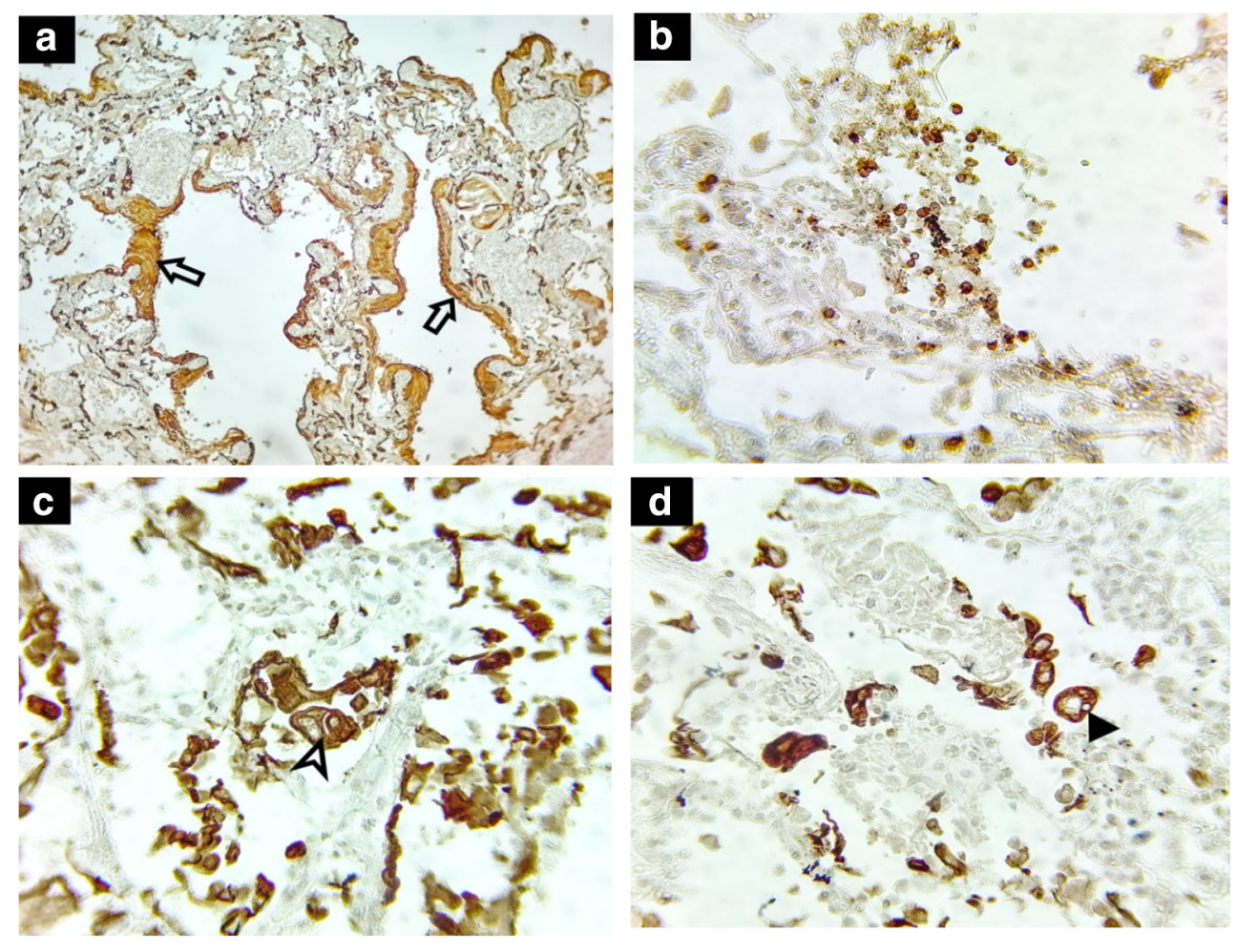

\section{Case 2}

The second case was a male patient, 27 years of age who was found dead in his house. Before the autopsy was performed, we checked his medical history, and we found out that he requested an ambulance 6 days before his death. On that occasion, he was examined in the hospital's emergency department for dry cough and shortness of breath. However, there was no history of recent travel or known exposure to sick contacts; thus he was not tested at that time for SARS-CoV2. He was discharged from the emergency unit with recommendation of further evaluation at the Pulmonary Disease Department; however, he was found dead 6 days later. Searching further through his medical history, we found out that 1 year ago, he had two hospitalizations for bronchopneumonia, acute respiratory failure, hypercapnic respiratory acidosis, septal deviation, ethmoidal sinusitis, and sleep apnea syndrome (which remained in observation). Both times he was admitted to hospital in the past, he was in a coma. Two months prior to his death, he had another admission with influenza virus infection. He underwent treatment, and he gradually recovered. It is important to mention that he suffered from class 1 obesity and he was a smoker.

\section{Autopsy findings}

External examination of the body revealed the absence of trauma and no specific signs that could have indicated a violent cause of death. Mild edema and vascular congestion and no ischemic or hemorrhagic lesions were found upon cross section of the cerebral hemispheres. The thoracic cavity lacked any fluid accumulations. The visceral pleura was clean, smooth, and glassy with the presence of groups of small brown to red papule-like lesions on the subpleural surface of both the lungs accompanied by small to medium foci of subpleural retraction zones of the pulmonary parenchyma. The lungs were heavy and congested with lack of crepitations upon palpation. Cross section revealed a fleshy dark red parenchyma of elastic consistency with dirty dark deoxygenated liquid blood that leaked from the blood vessels, and a moderate frothy pink fluid was discharged upon compression (Fig. 4). There was a mild dilatation of the right atrial and ventricular cavity. No other pathological findings were observed upon macroscopic examination of the other organs (Tables 2).

\section{Microscopic findings}

Microscopic examination of the pulmonary tissue revealed large areas of alveolar damage with destruction of the alveolar wall lining and intra-alveolar septa, marked vascular congestion, accompanied by intra-alveolar hemorrhage. In the alveolar space, we found large numbers of hemosiderin-laden macrophages, detached pneumocytes, and a rich intra-alveolar eosinophilic homogenous material suggesting marked pulmonary edema. The detached type II pneumocytes within the alveolar space were enlarged with a round to oval structure, a big irregular nucleus with prominent nucleolus, and coarse clumped chromatin at the edge of the nucleus. Sometimes binucleation was present. All 


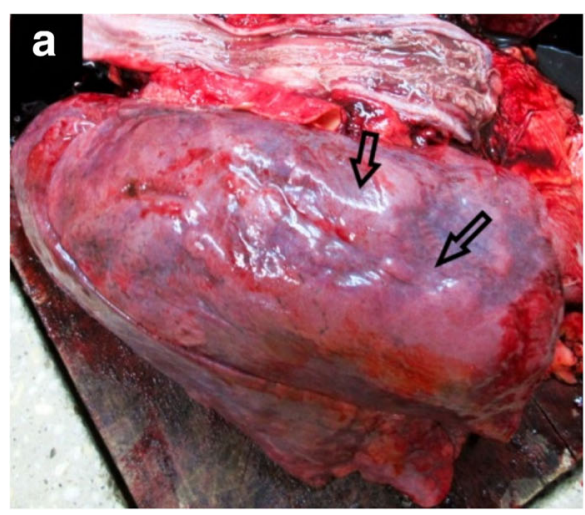

Fig. 4 Macroscopic aspect of lung (case 2). a (arrows) Subpleural parenchymal retraction zones. b (arrow heads) Groups of small brown to red papule-like lesions on the subpleural surface of both lungs. $\mathbf{c}$ Fleshy

these changes suggest viral cytopathic effect. These cytopathic cells tend to form groups like in the other case, mimicking multinucleated giant cells. Focal areas of mild pneumocyte hyperplasia were observed. There was only focal presence of hyaline membranes. Foci of lymphocytic inflammatory infiltration could be seen with an affinity for the perivascular spaces and around the small to medium size bronchi. In some areas, the lymphocytes tend to invade the vascular wall but with no fibrinoid necrosis formation, suggesting a mild vasculitic reaction. The epithelium of the bronchi was detached and eroded, and there was mild glandular hyperplasia within the bronchus walls. The blood vessels were markedly dilated with hematic content, the walls of these vessels were fibrotic as well as the perivascular space with fibrotic trabecula extending from the spaces to the intra-alveolar septum. In some areas of the affected lung, there was a presence of necrosis, with cellular debris and neutrophilic inflammatory response. Small blood vessels in these areas are microthrombotic but with no signs of leukocytoclastic vasculitis upon the small, medium, or large blood vessels of the examined lung tissues (Table 3 and Fig. 5).

Microscopic examination of the myocardium revealed areas of small vessel thrombosis but with no histological signs of ischemia. There was marked vascular congestion, mild edema between the muscle fibers, and no inflammatory infiltrate in the examined specimens. The myocardial architecture was normal beside scattered areas of myocardial fibers that tended to form contraction bands, most likely due to acute circulatory disorders originated immediately before death. The thickness of the arteries was normal with preserved luminal permeability and no sign of atherosclerosis or myocarditis (Fig. 6).

\section{Case 3}

The deceased was a 70-year-old man with a complex medical history of hypertension, ischemic cardiomyopathy, chronic heart failure (NYHA III), mitral insufficiency, tricuspid insufficiency, atrial fibrillation, aortocoronary bypass (in 2008), chronic renal failure, generalized atherosclerosis, chronic rhinitis, and chronic pharyngitis. Two months prior to his death, he was prescribed with anticoagulant drugs for his cardiovascular diseases. One day prior to death, he was admitted to hospital for melena and hematochezia, having blood pressure $94 / 39 \mathrm{mmHg}$, and $\mathrm{SaO} 2=75 \%$. Laboratory specimens drawn on that day detected a hypocoagulatory state, acute renal failure, increased level of C-reactive protein, increased white blood cell count with neutrophilia, severe hemorrhagic anemia translated by decreased red blood cell count, and extremely low level of hemoglobin $(3.8 \mathrm{~g} / \mathrm{dl})$ (Table 1). Due to his condition, he presented cardiac arrest without response to resuscitation, so death was declared. There was no history of recent travel or known exposure to SARS-CoV-2-positive contacts.

\section{Autopsy findings}

No specific pathological findings were observed upon external examination of the body. The cranial cavity was not opened. The examination of the thoracic cavity revealed about $250 \mathrm{ml}$ of clear serous fluid in the pleural space, on each side. The inferior lobes of each lung and part of the middle lobe of the right lung had a fleshy appearance, but with no increase in volume, the surface of the lobes was smooth and glassy. Upon palpation, the consistency was more elastic with areas that lack crepitations. There was compensatory emphysema at the level of the bilateral superior lobes. Dark deoxygenated liquid blood leaked upon dissection of the lung parenchyma, and a mild frothy pink fluid was discharged upon compression. The sectioned surface had small areas of a more intense reddish color between stretched areas of dark purple color. Dilatation of the right atrium and right ventricle and left ventricular hypertrophy was observed. The coronary arteries suffered extreme atherosclerosis, with marked narrowing of the arterial lumen. Upon dissection we found areas of myocardial fibrosis secondary to an old myocardial infarction. The gastric mucosa was hyperemic with small areas of diffuse hemorrhage. Moderate amount of hematic content was found within 
Fig. 5 Microscopic aspect of lung (case 2) -hematoxylin-eosin ( $\times$

$100, \times 400)$. a $(\times 100)$ Destruction of alveolar walls with marked congestion, intra-alveolar hemorrhage, and diffuse desquamation of pneumocytes. b (arrows) $(\times 400)$ Moderate perivascular lymphocytic inflammatory response with invasion of vascular walls. $\mathbf{c}(\times$ 400) Groups of hemosiderinladen macrophages (arrow heads) with microthrombi formation within a small blood vessel (star). d $(\times 400)$ Numerous pneumocytes who underwent viral cytopathic effect, one binucleated (triangle)
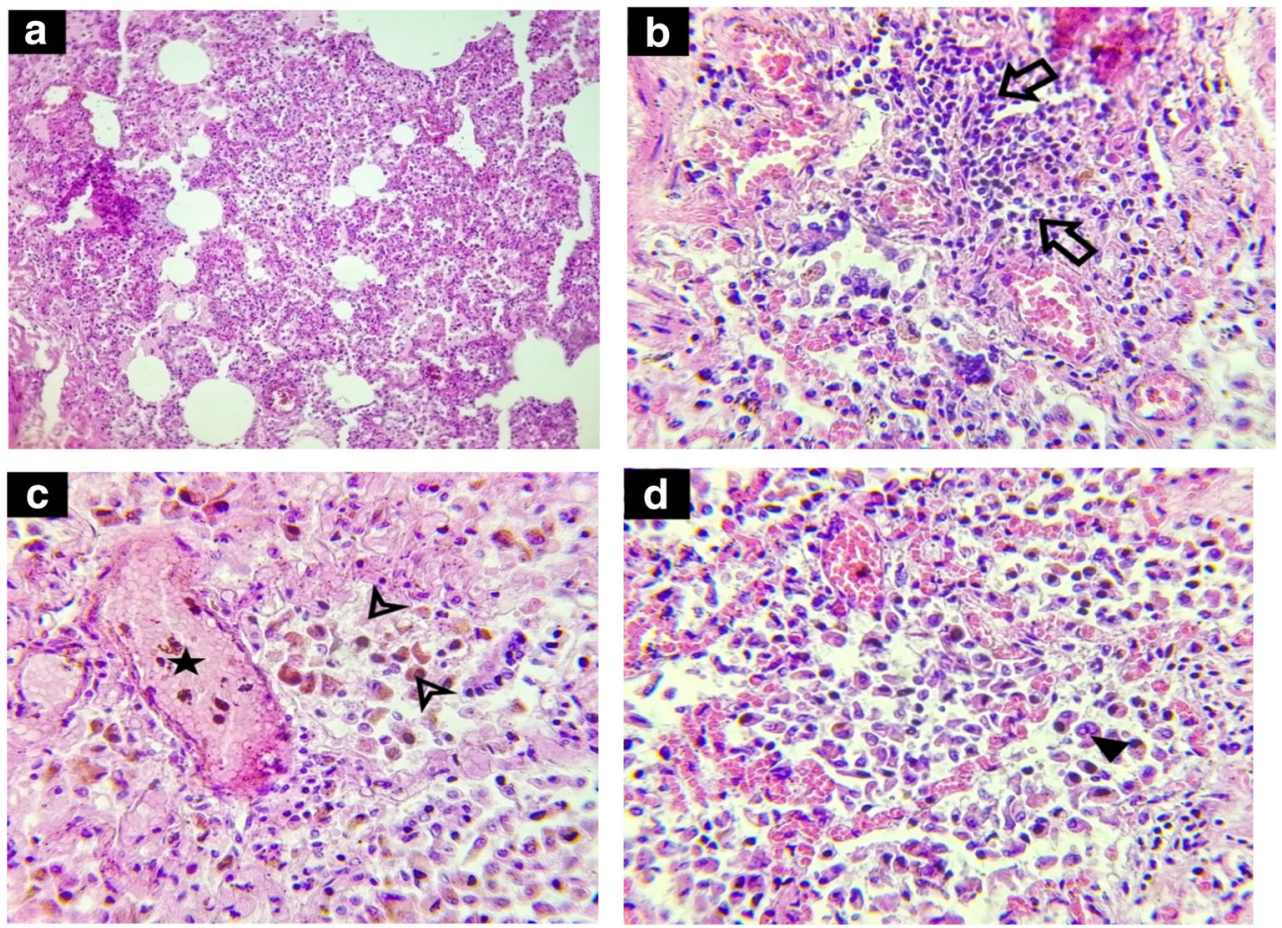

the intestinal lumen, but upon examination of the mucosa, there were no signs of ulcers or hemorrhagic tumors. The liver was increased in volume with diffuse fibrosis and regenerative nodules. The spleen was mildly decreased in volume (Table 2).

\section{Microscopic findings}

In this case, the pulmonary architecture was relatively preserved, with lack of diffuse lung injury and hyaline membrane

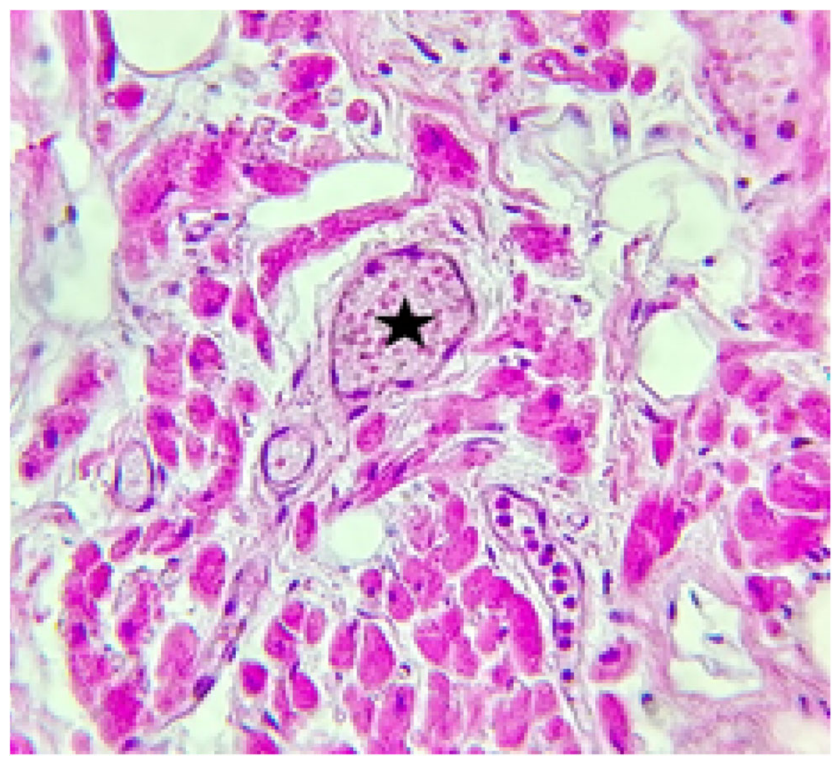

Fig. 6 Microscopic aspect of myocardium (case 2) - hematoxylin eosin $(\times 400)$. Small vessel thrombosis (star) formation. There was marked vascular congestion with the presence of numerous dilated blood vessels with hematic content, focal areas where the intra-alveolar walls were ruptured and focal areas of pulmonary edema. Detachment of the alveolar lining with scattered pneumocytes throughout the alveolar space and mild to moderate type II pneumocyte hyperplasia were also a constant finding. These pneumocytes had an increased volume with rich eosinophilic cytoplasm, a round to oval sometimes irregular nucleus with round prominent nucleolus and course, clumped chromatin, mainly at the edge of the nucleus. Sometimes binucleation was present. These type II pneumocytes had suffered viral cytopathic effect, similar with the other two cases. There was a mild to moderate lymphocytic inflammatory reaction, more evident in the perivascular region, with some lymphocytes invading the vascular wall but without fibrinoid necrosis. There were areas of fibrosis within the intra-alveolar septum and atelectasis zones. Some small blood vessels had clumped red blood cells in the lumen, forming microthrombi (Table 3 and Fig. 7).

The architecture of the renal parenchyma was preserved. The glomeruli were shrunken, and the Bowman space was widened. There was focal vacuolar degeneration in the cytoplasm of some proximal convoluted tubule cells and cellular debris in the luminal space, consistent with a degree of acute tubular necrosis, most probably by renal hypoperfusion. There is also marked peritubular congestion more accentuated in the medullary parenchyma.

There is diffuse disruption of the normal hepatic architecture with regenerative nodules of hepatocytes, 


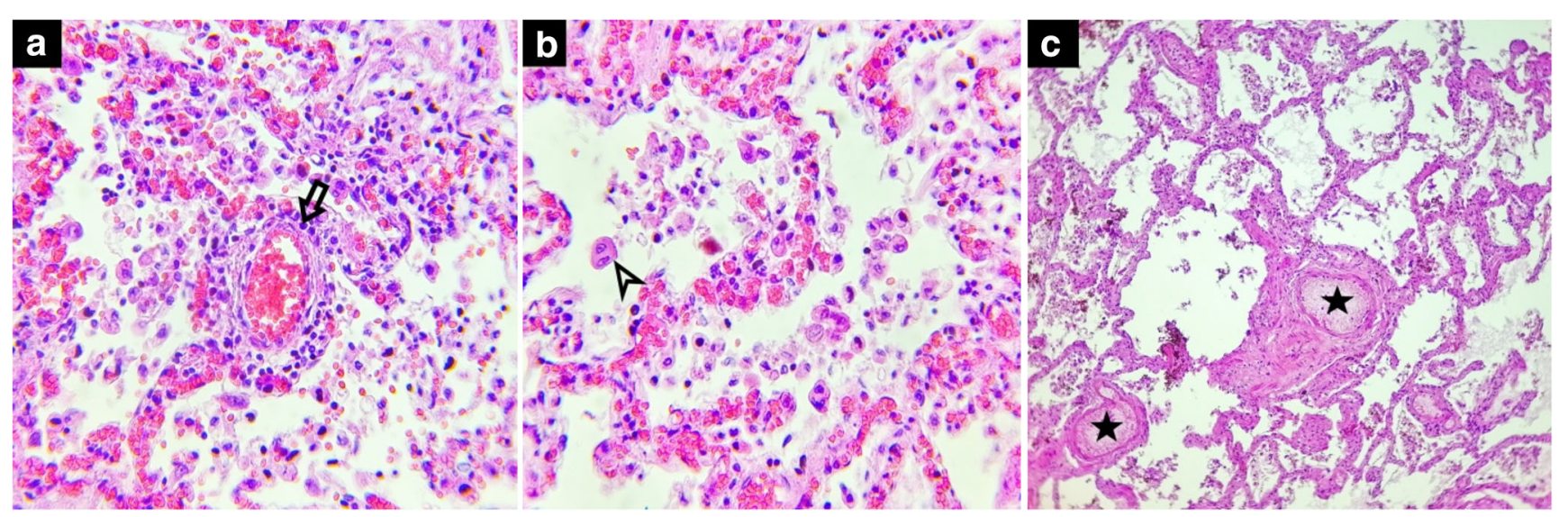

Fig. 7 Microscopic aspect of lung (case 3) -hematoxylin-eosin $(\times 100, \times$ 400). a (arrow) $(\times 400)$ Mild to moderate perivascular lymphocytic infiltrate with some lymphocytes with tendency of invading the vascular wall. b $(\times 400)$ Viral cytopathic changes within type II pneumocytes, one with binucleation (arrow head). c (stars) $(\times 100)$ Microthrombi formation within the small blood vessels of the lung surrounded by fibrous connective tissue that bridges between portal tracts, consistent with chronic liver disease. Within this collagenous tissue, there were scattered lymphocytes and a proliferation of bile ducts.

Microscopy of the spleen like in our first case showed an abnormal architecture with marked congestion, red pulp necrosis and white pulp atrophy, with absence of lymphoid follicles. The residual lymphoid tissue was found around the central arteries. The capsule was intact.

\section{Discussion}

In 2 out of 3 cases, there was no known positive COVID-19 contact and no recent travel history to or from countries with high number of infections in that period of time. In case 1, it was known that the husband was found positive during his one admission, but the chronological order of the infections could not be determined.

In two out of these three cases, the cause of death was a result of direct lung injury due to viral pneumonia, in contrast to our third case where the cause of death was due to a massive diffuse intestinal hemorrhage after an anticoagulant drug overdose in a patient with undiagnosed hepatic cirrhosis.

For the two cases with hospital admissions prior to their death, the laboratory findings were consistent with an inflammatory response due to infection. Complete blood count showed leukocytosis with mild neutrophilia and mild lymphocytopenia, with a C-reactive protein of $307.17 \mathrm{mg} / 1$ in our first case and a C-reactive protein of $14.12 \mathrm{mg} / \mathrm{l}$ in our last case.

The lungs were heavy, congested with an elastic consistency, and lack of crepitations upon palpation in cases 1 and 2, the same cases in which the direct cause of death was due to acute lung injury from SARS-CoV-2 infection. In case number 3 , the inferior lobes of each lung and part of the middle lobe of the right lung had a fleshy appearance, but with no increase in volume. Upon cross section, the lung tissues examined had a fleshy dark red or dark brown appearance, with patchy consolidations and with focal areas of normal parenchyma, more or less depending on the severity of pulmonary damage. Pulmonary congestion and edema were also a constant finding. In our first case, we found multiple dark grey lymphadenopathies up to $20 \mathrm{~mm}$ in diameter, at the level of the bilateral pulmonary hilum and mediastinum.

We found several important microscopic lesions of the lungs, which helped us draw a clearer picture of the pathology of COVID19 and help us better understand the pathogenesis and pathophysiology of the new viral disease. The presence of alveolar wall destruction with detachment of the surface epithelial lining with various degree of type II pneumocyte hyperplasia confirms that impaired gas exchange by loss of alveolar-capillary membrane can still be considered an important pathophysiological mechanism, in which SARS-CoV-2 produces acute respiratory distress syndrome (ARDS). These findings were backed up by previews studies [2-7].

The consistent presence of pneumocytes increased in volume, with big round to oval, sometimes irregular nucleus, prominent central or peripheral nucleolus and clumped, course chromatin, with some cells that present binucleation or small, pyknotic, intense basophilic nuclear inclusions situated to the periphery of the nucleus, can be interpreted as a viral cytopathic effect, thus confirming the viral origin of the pulmonary infection. Pernazza A. et al. described similar findings of reactive hyperplasia and focal pneumocytes with nuclear inclusions [8], as well as Suess C. et al. who found patchy and severe type II pneumocyte hyperplasia with atypically enlarged pneumocytes with large nuclei, amphophilic granular cytoplasm, and prominent nucleoli showing viral cytopathiclike changes [7].

In all three cases investigated, we discovered areas where these cells tend to form clusters and cohere one to another, 
forming giant cell-like syncytial aggregates, which can be mistaken with multinucleated giant cells of histiocytic origin. Like in our study, Zhe Xu*, Lei Shi* et al. described these cells as multinucleated syncytial cells with atypical enlarged pneumocytes characterized by large nuclei, amphophilic granular cytoplasm, and prominent nucleoli that were identified in the intra-alveolar spaces, showing viral cytopathic-like changes and no obvious intracytoplasmic or intra- nuclear viral inclusions [9], as well as previews studies in the literature [3]. After immunohistochemical studies, we confirmed that indeed these cells are of pneumocytic origin with cytokeratin positivity.

Hyaline membranes, specific of diffuse alveolar damage, were found more prominent in our first case and only focally on our second case.

The presence of microthrombi in the lung parenchyma was found constantly, and in our 27-year-old who died at home (case 2), we found these microthrombi even in some areas of the myocardium. The presence of microthrombi was described in many other case reports suggesting an important pattern of SARS-CoV-2 pathogenesis $[4,5,7]$.

We have put the problem that our pulmonary pathological findings were, in some degree, caused by ventilator-induced lung injury, but we concluded that this was not the case of our three patients because, to our knowledge, only our first patient was put on a ventilator but for a short period of time right before death.

Mild vasculitic reaction consistent with invasion of pulmonary vascular wall by lymphocytes but with no presence of fibrinoid necrosis was found upon two out of three cases (case 2 and case 3). This finding is consistent with a form of endotheliitis, discussed in detail by Varga Z. et al. who found viral inclusion structures upon studying under an electron microscope endothelial cells of a patient's kidney who was confirmed with SARS-CoV-2 infection. Histopathology described accumulation of inflammatory cells associated with endothelium, as well as apoptotic bodies, in the heart, small bowel, and lung [10]. Other studies confirmed the same findings as lymphocytic capillaritis within the lung and viral endotheliitis of myocardial vessels [11]. Beside the lungs, we could not find specific signs of vasculitis, perivasculitis, and capillaritis, and we concluded that our inflammatory response around the vessels of the other organs was a perivascular inflammatory infiltrate.

The first two cases presented focal neutrophil infiltrate in the lung tissues examined. Other publications described more or less the same microscopic lesions $[4,7,12,13]$.

The myocardium tissues presented small areas of contraction bands and scattered lymphocytes; no signs of myocarditis were present. The same conclusion was expressed by Sharon E. Fox et al. [14]. Dettmeyer et al. confirmed the presence of lymphocytic myocarditis in the right ventricle of a SARSCoV-2-positive case.
Microscopy of the kidney revealed focal areas of acute tubular necrosis upon the proximal convoluted tubules overlaying postmortem changes. Other studies revealed the same injury upon the proximal tubules with loss of brush border and nonisometric vacuolization, which partially may be caused by direct virulence of SARS-CoV-2 [15]. Some authors described microscopic alterations consistent with collapsing glomerulonephritis [16, 17]; however, this was not present in our specimens. In case 1, small focal microthrombosis of the glomerular capillaries was found upon microscopic examination.

Immunohistochemical studies done to define our type of lymphocytic inflammatory infiltrate in our lung cut sections established that mostly CD3, CD5-positive T lymphocytes, and only scattered CD20-positive B lymphocytes were found during examination, consistent with recent literature $[4,8]$.

\section{Compliance with ethical standards}

Conflict of interest The authors declare that they have no conflict of interest.

Human rights statements and informed consent All procedures performed in studies involving human participants were in accordance with the ethical standards and with the 1964 Helsinki declaration and its later amendments or comparable ethical standards. All personal data were anonymized in order to protect the identity of our patients. Autopsy results including histology may be used anonymously for scientific purpose.

Animal rights This article does not contain any studies with animal subjects performed by any of the authors.

\section{References}

1. Keyser FH, Bienz KA, Eckert J, Zinkernagel RM (2005) Medical microbiology. Thieme

2. Tian S, Xiong Y, Liu H, Niu L, Guo J, Liao M, Xiao SY (2020) Pathological study of the 2019 novel coronavirus disease (COVID19) through postmortem core biopsies. Mod Pathol 33:1007-1014. https://doi.org/10.1038/s41379-020-0536-x

3. Zhang H, Zhou P, Wei Y, Yue H, Wang Y, Hu M, Zhang S, Cao T, Yang C, Li M, Guo G, Chen X, Chen Y, Lei M, Liu H, Zhao J, Peng P, Wang CY, Du R (2020) Histopathologic changes and SARS-CoV-2 immunostaining in the lung of a patient with COVID-19. Annals of Internal Medicine 172(9):629-632. https:// doi.org/10.7326/M20-0533

4. Barton LM, Duval EJ, Stroberg E, Ghosh S, Mukhopadhyay (2020) COVID-19 Autopsies, Oklahoma, USA. Am J Clin Pathol 153: 725-733

5. Fitzek A, Sperhake J, Edler C, Schröder AS, Heinemann A, Heinrich F, Ron A, Mushumba H, Lütgehetmann M, Püschel K (2020) Evidence for systematic autopsies in COVID-19 positive deceased: case report of the first German investigated COVID-19 death. Rechtsmedizin 30:184-189

6. Hanley LS, Lucas SB, Youd E, Swift B, Osborn M (2020) Autopsy in suspected COVID-19 cases. J Clin Pathol 73:239-242. https:// doi.org/10.1136/jclinpath-2020-206522 
7. Suess C, Hausmann R (2020) Gross and histopathological pulmonary findings in a COVID-19 associated death during self-isolation. Int J Leg Med. https://doi.org/10.1007/s00414-020-02319-8

8. Pernazza A, Mancini M, Rullo E, Bassi M, de Giacomo T, Della Rocca C, d'Amati G (2020) Early histologic findings of pulmonary SARS-CoV-2 infection detected in surgical specimen. Virchows Arch. https://doi.org/10.1007/s00428-020-02829-1

9. Xu Z, Shi L, Wang Y, Zhang J, Huang L, Zhang C, Liu S, Zhao P, Liu H, Zhu L, Tai Y, Bai C, Gao T, Song J, Xia P, Dong J, Zhao J, Wang F-S (2020) Pathological findings of COVID-19 associated with acute respiratory distress syndrome. Lancet Respir Med 8: 420-422. https://doi.org/10.1016/S2213-2600(20)30076-X

10. Varga Z, Flammer AJ, Steiger P, Haberecker M, Andermatt R, Zinkernagel AS, Mehra MR, Schuepbach RA, Ruschitzka F (2020) Moch H (2020) Endothelial cell infection and endotheliitis in COVID-19. Lancet 395(10234):1417-1418. https://doi.org/10. 1016/S0140-6736(20)30937-5

11. Dettmeyer R, Lasczkowksi G, Weber A, Wolter T, KernbachWighton G (2020) Histopathological findings following SARSCoV-2 infection with and without therapy - report of 3 autopsies. Rechtsmedizin 30. https://doi.org/10.1007/s00194-020-00408-x

12. Edler C, Schröder AS, Aepfelbacher M, Fitzek A, Heinemann A, Heinrich F, Klein A, Langenwalder F, Lütgehetmann M, Meißner K, Püschel K, Schädler J, Steurer S, Mushumba H, Sperhake JP (2020) Dying with SARS-CoV-2 infection - an autopsy study of the first consecutive 80 cases in Hamburg, Germany. Int J Legal Med 134:1275-1284. https://doi.org/10.1007/s00414-020-02317$\mathrm{W}$

13. Aguiar D, Lobrinus JA, Schibler M, Fracasso T, Lardi C (2020) Inside the lungs of COVID-19 disease. Int J Legal Med 134:12711274. https://doi.org/10.1007/s00414-020-02318-9

14. Fox SE, Akmatbekov A, Harbert JL, Li G, Brown JQ, Vander Heide RS (2020) Pulmonary and Cardiac Pathology in Covid-19: The first autopsy series from New Orleans. medRxiv. https://doi. org/10.1101/2020.04.06.20050575

15. Hua S, Yang M, Cheng W, Yi L-X, Tang F, Zhu H-Y, Yi F, Yang H-C, Fogo AB, Nie X, Zhang C (2020) Renal histopathological analysis of 26 postmortem findings of patients with COVID-19 in China. Kidney International 98:219-227. https://doi.org/10.1016/j. kint.2020.04.003

16. Nasr SH, Kopp JB (2020) COVID-19-associated collapsing glomerulopathy: an emerging entity. Kidney Int Rep 5:759-761

17. Peleg Y, Kudose S, D'Agati V, Siddali E, Ahmad S, Nickolas T, Kisselev S, Gharavi A, Canetta P (2020) Acute kidney injury due to collapsing glomerulopathy following COVID-19 infection. Kidney Int Rep 5:940-945

Publisher's note Springer Nature remains neutral with regard to jurisdictional claims in published maps and institutional affiliations. 